\title{
Glucose-triggered signalling in Saccharomyces cerevisiae: different requirements for sugar phosphorylation between cells grown on glucose and those grown on non-fermentable carbon sources
}

\author{
Maria Beatriz Pernambuco, ${ }^{1}$ Joris Winderickx, ${ }^{1}$ Marion Crauwels, ${ }^{1}$ \\ Gerard Griffioen, ${ }^{2}$ Willem H. Mager ${ }^{2}$ and Johan M. Thevelein ${ }^{1}$
}

\begin{abstract}
Author for correspondence: Johan M. Thevelein. Tel: +3216321507 or 321500 . Fax: +32 16321979. e-mail : Johan.Thevelein@bio.kuleuven.ac.be
\end{abstract}

\footnotetext{
1 Laboratorium voor Moleculaire Celbiologie, Katholieke Universiteit te Leuven, Kardinaal

Mercierlaan 92, B-3001

Leuven-Heverlee, Flanders, Belgium

2 Department of Biochemistry and Molecular Biology, Vrije Universiteit, de Boelelaan 1083, 1081 HV Amsterdam, the Netherlands
}

Addition of glucose or fructose to cells of the yeast Saccharomyces cerevisiae grown on a nonfermentable carbon source triggers within a few minutes posttranslational activation of trehalase, repression of the $\mathrm{CTI}$ (catalase) and SSA3 (Hsp70) genes, and induction of the ribosomal protein genes RPL1, RPL25 and RPS33. By using appropriate sugar kinase mutants, it was shown that rapid glucose- or fructose-induced activation of trehalase requires phosphorylation of the sugar. On the other hand, partial induction of RPL1, RPL25 and RPS33 as well as partial repression of CTI1 and SSA3 were observed in the absence of sugar phosphorylation. In glucose-grown nitrogen-starved yeast cells readdition of a nitrogen source triggers activation of trehalase in a glucose- or fructose-dependent way, but with no apparent requirement for phosphorylation of the sugar. Repression of CTI1 and SSA3 under the same conditions was also largely dependent on the presence of the sugar and also in these cases there was a strong effect when the sugar could not be phosphorylated. Nitrogen induction of RPL1, RPL25 and RPS33 was much less dependent on the presence of the sugar, and only phosphorylated sugar caused a further increase in expression. These results show that two glucosedependent signalling pathways, which can be distinguished on the basis of their requirement for glucose phosphorylation, appear to be involved in activation of trehalase, repression of CTI1 and SSA3 and induction of ribosomal protein genes. They also show that nutrient-induced repression of CTI1 and SSA3 is not a response to improvement of the growth conditions because the addition of nonmetabolizable sugar does not ameliorate the growth conditions. Similarly, the upshift in ribosomal protein synthesis cannot be a response to increased availability of energy or biosynthetic capacity derived from glucose, but it is apparently triggered to a significant extent by specific detection of glucose as such.

Keywords : glucose signalling, trehalase, catalase, Hsp70, ribosomal protein genes

\section{INTRODUCTION}

The addition of glucose, fructose or a related rapidly fermented sugar to cells of the yeast Saccharomyces cerevisiae growing on a nonfermentable carbon source, like glycerol or ethanol, triggers an extensive series of regulatory responses at both the post-translational and transcriptional level (recent review: Thevelein \& Hohmann, 1995).
For glucose-induced activation of cAMP synthesis (Beullens et al., 1988), inactivation of fructose-1,6bisphosphatase (Gancedo \& Gancedo, 1979; Entian et al., 1983 ) and most other non-cAMP-mediated responses, such as glucose repression (Entian, 1986), activation of plasma membrane $\mathrm{H}^{+}$-ATPase (Becher dos Passos et al., 1992) and induction of PDC1 (Boles et al., 1993), phosphorylation of the glucose is essential, as shown by 
loss of the response in mutants unable to phosphorylate glucose. The addition of glucose or fructose to cells growing on a nonfermentable carbon source is well known to trigger also a rapid increase in the growth rate, which is preceded by a characteristic upshift in the synthesis of ribosomal RNA and protein (Kief $\&$ Warner, 1981; Donovan \& Pearson, 1986; Mager \& Planta, 1991). Requirement of sugar phosphorylation for this upshift has not been studied up to now.

Starvation of yeast cells on a glucose-containing medium for any other essential nutrient, such as nitrogen, phosphate or sulfate, will cause them to arrest in the cell cycle and enter a resting state called G0. These cells continue to ferment glucose, but at a lower rate, and they show accumulation of trehalose and glycogen, induction of the CTT1 gene, encoding catalase, several genes encoding heat shock proteins, such as $S S A 3$, and also repression of the whole spectrum of ribosomal protein genes (review: Werner-Washburne et al., 1993). Re-addition of the missing nutrient triggers rapid activation of trehalase and mobilization of trehalose (Hirimburegama et al., 1992), activation of glycogen phosphorylase, inactivation of glycogen synthase and mobilization of glycogen (François et al., 1988), repression of $C T T 1$ and $S S A 3$ (Bissinger et al., 1989; Werner-Washburne et al., 1989) and induction of the ribosomal protein genes (Pearson \& Haber, 1980; Mager \& Planta, 1991). All the effects associated with the re-induction of growth under these conditions are at least in the long term dependent on the presence of both a fermentable carbon source and a complete growth medium. Therefore, we have called the signalling pathway involved in these phenomena the 'fermentable-growthmedium-induced pathway' (Thevelein \& Hohmann, 1995). At present, it is unclear whether more than one independent pathway is involved in triggering the different target processes.

The metabolic changes measured in this work, i.e. activation of trehalase, repression of $C T T 1$ and $S S A 3$, and induction of the ribosomal protein genes RPL1, RPL25 and RPS33, are clearly correlated under a variety of conditions with growth induction or growth stimulation (Pearson \& Haber, 1980; Thevelein, 1984; Thevelein \& Beullens, 1985; Bissinger et al., 1989; Werner-Washburne et al., 1989; Mager \& Planta, 1991; Hirimburegama et al., 1992). Whether glucose-triggered signalling involved in growth induction or growth stimulation itself requires phosphorylation of glucose is difficult to measure directly because glucose also provides through its metabolism energy and intermediates which are an essential requirement for growth. In order to investigate the nutrient-induced signalling requirements for growth induction, one is limited to studying growthrelated events as markers. Interestingly, it has recently been shown that a number of growth-related events in yeast are triggered in a non-cAMP-mediated way by glucose which could not be phosphorylated (Granot \& Snyder, 1991, 1993). In addition, incubation of stationaryphase cells for a certain period of time in the presence of unphosphorylated glucose shortened the time required for bud emergence when the cells were subsequently transferred to a complete growth medium (Granot \& Snyder, 1991, 1993). This might indicate a lack of sugar phosphorylation requirement for the control of growth, although indirect mechanisms cannot be excluded.

In $S$. cerevisiae three enzymes are known to be capable of phosphorylating glucose. Glucokinase, encoded by the GLK1 gene, is specific for glucose, whereas hexokinases PI and PII, encoded by $H X K 1$ and $H X K 2$, respectively, phosphorylate both glucose and fructose (Fraenkel, 1982). Requirement of sugar phosphorylation is easily studied in cells of triple kinase or double hexokinase mutants, grown on a nonfermentable carbon source, by adding glucose or fructose, respectively. Similarly, requirement of sugar phosphorylation for responses in glucose-grown cells can easily be studied in cells of a $b \times k 1 h \times k 2$ double mutant by washing glucose away and re-incubating the cells with fructose (e.g. Gancedo \& Gancedo, 1979; Beullens et al., 1988; Walsh et al., 1991; Becher dos Passos et al., 1992; Boles et al., 1993). This approach is more reliable than the use of glucose analogues since these might not be detected properly by glucose-sensing systems.

\section{METHODS}

Strains, media and growth conditions. The following isogenic sets of yeast strains were used: (1) WAY.5-4A (MATa ura3-52

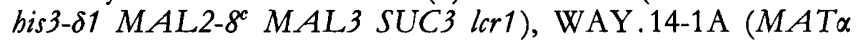
ura3-52 bis3-81 leu2-3,112 bxk2:: LEU2 glk1:: LEU2 MAL2-8c $M A L 3$ SUC3 lor 1$)$, WAY.glk1-1A ( $M A T$ a ura3-52 bis3- $\delta 1$ leu2-3,112 bxk1::HIS3 bxk2::LEU2 MAL2-8 MAL3 SUC3 lcr1), WAY.glk1-5C (MATa trp1-289 bis3- $\delta 1$ leu2-3,112 bxk1:: HIS3 glk1::LEU2 MAL2-8c MAL3 SUC3 lcr1) (generously provided by K. D. Entian) and PD1501 (MATa bis3- $\delta 1$ ura3-52 leu2-3,112 bxk1::HIS3 bxk2::LEU2 glk1::LEU2 $M A L 2-8$ MAL3 SUC3 lor1); (2) YSH327 (MATa leu2-3/112 ura3-1 trp1-1 bis3-11/15 ade2-1 can1-100 GAL SUC2 bxk1::HIS3 bxk2::LEU2) and YSH757 (MATa leu2-3/112 ura3-1 trp1-1 bis3-11/15 ade2-1 can1-100 GAL SUC2 bxk1::HIS3 bxk2::LEU2 glk1::LEU2) (both strains are isogenic to W303-1A; they were used for the experiment shown in Fig. 4a). Cells were grown at $30^{\circ} \mathrm{C}$ on YPD $[4 \%(w / v)$ glucose, $2 \%(\mathrm{w} / \mathrm{v})$ peptone and $1 \%(\mathrm{w} / \mathrm{v})$ yeast extract] or YPglycerol $[3 \%(\mathrm{v} / \mathrm{v})$ glycerol, $2 \%(\mathrm{w} / \mathrm{v})$ peptone and $1 \%$ $(\mathrm{w} / \mathrm{v})$ yeast extract]. Nitrogen starvation was carried out with exponential-phase cells grown on YPD and subsequently starved for nitrogen at $30^{\circ} \mathrm{C}$ on a medium containing $4 \%$ glucose and $0.17 \%$ Difco Yeast Nitrogen Base without amino acids and without ammonium sulfate, for a period of $24 \mathrm{~h}$ at a cell density of 4-8 $\mathrm{mg}$ cells (wet weight) $\mathrm{ml}^{-1}$. At the end of the starvation period the remaining glucose level was at least $20 \mathrm{mM}$.

Activation of trehalase. Exponential-phase YPglycerol-grown cells were collected by centrifugation, washed twice with icecold $25 \mathrm{mM}$ MES/KOH buffer ( $\mathrm{pH}$ 6) and resuspended at a cell density of $25 \mathrm{mg} \mathrm{ml}^{-1}$ in $25 \mathrm{mM} \mathrm{MES} / \mathrm{KOH}$ buffer ( $\mathrm{pH} \mathrm{6}$ ). The cells were pre-incubated at $30^{\circ} \mathrm{C}$ for $10 \mathrm{~min}$ before the first sample was taken. Activation of trehalase was triggered by addition of $4 \%(\mathrm{w} / \mathrm{v})$ glucose or fructose. Nitrogen-starved cells were collected by centrifugation, washed twice with icecold $25 \mathrm{mM}$ MES/KOH buffer $(\mathrm{pH} 6)$ and resuspended at the same cell density in fresh nitrogen starvation medium with either glucose or fructose (each $4 \%$ ). They were pre-incubated at $30^{\circ} \mathrm{C}$ for $30 \mathrm{~min}$ before the first sample was taken. For nitrogen-induced activation of trehalase $10 \mathrm{mM}$ asparagine and 
the amino acids for which the strain is auxotrophic were used as nitrogen source.

Sampling, preparation of crude extracts and trehalase assay. Samples containing $75 \mathrm{mg}$ (wet weight) cells were taken at the indicated times and quickly mixed with $45 \mathrm{ml}$ ice-cold water. The cells were collected by centrifugation for $3 \mathrm{~min}$ at $4{ }^{\circ} \mathrm{C}$. The pellet was resuspended in $0.5 \mathrm{ml}$ ice-cold $50 \mathrm{mM} \mathrm{MES} / \mathrm{KOH}$ buffer ( $\mathrm{pH} 7$ ) containing $50 \mu \mathrm{M} \mathrm{CaCl}_{2}$. The cells were broken by vigorous mixing for $90 \mathrm{~s}$ in a small pre-cooled test tube containing $1.5 \mathrm{~g}$ glass beads $(0.5 \mathrm{~mm}$ diameter $)$. The crude enzyme extract was centrifuged for $3 \mathrm{~min}$ at 13000 r.p.m. in a microcentrifuge at $4{ }^{\circ} \mathrm{C}$. The supernatant was dialysed overnight at $4{ }^{\circ} \mathrm{C}$ in a microdialysis apparatus against $5 \mathrm{mM} \mathrm{MES} / \mathrm{KOH}$ buffer ( $\mathrm{pH}$ 7) containing $50 \mu \mathrm{M} \mathrm{CaCl}_{2}$. For trehalase assay, $10 \mu \mathrm{l}$ dialysed extract was incubated with $140 \mu \mathrm{l}$ water and $100 \mu \mathrm{l}$ substrate buffer $(250 \mathrm{mM}$ trehalose in $62.5 \mathrm{mM} \mathrm{MES} / \mathrm{KOH}$ buffer, $\mathrm{pH} 7$, with $125 \mu \mathrm{M} \mathrm{CaCl}_{2}$ ) for $30 \mathrm{~min}$ at $30^{\circ} \mathrm{C}$. The reaction was stopped by boiling for $3 \mathrm{~min}$ at $100^{\circ} \mathrm{C}$. The glucose liberated was assayed by the glucose oxidase/peroxidase method. Protein was determined by the Lowry procedure. Specific activity of trehalase is expressed as nmol glucose liberated $\min ^{-1}$ (mg protein) ${ }^{-1}$.

RNA extraction and Northern blot analysis. Growth and starvation conditions were the same as those used for the trehalase activation experiments. Total RNA was extracted essentially as described previously by shaking cells with glass beads in the presence of acid, water-equilibrated phenol (Sherman et al., 1986). Equal amounts of RNA $\left(A_{\mathbf{2 6 0}}\right)$ were separated in $1 \%(\mathrm{w} / \mathrm{v})$ agarose gels, containing formaldehyde, transferred to a nylon membrane and hybridized with ${ }^{32} \mathrm{P}$ labelled DNA fragments of the coding region of CTT1, SS A3, RPL1, RPL25 or RPS33. The filters were then analysed using phosphorimager technology (Fuji, BAS1000; Software, PCBAS 2.0). In all cases equal amounts of RNA were loaded. Actin mRNA levels were used as standards but in stationary-phase cells actin mRNA levels were also lower compared to exponential-phase cells.

Chemicals. The fructose used was from Merck (quality: extra pure, cat. no. 5321).

\section{RESULTS}

When wild-type $S$. cerevisiae cells grow on a nonfermentable carbon source, they accumulate a high level of trehalose. Addition of a rapidly fermented sugar like glucose or fructose triggers an approximately fivefold activation of trehalase within a few minutes, resulting in rapid mobilization of trehalose (Van der Plaat, 1974; Thevelein \& Beullens, 1985). When glucose or fructose was added to glycerol-grown cells of a bxk1 bxk2 GLK1 strain, which is only able to phosphorylate glucose and not fructose, only glucose triggered activation of trehalase. Fructose had no effect (Fig. 1). In a strain able to phosphorylate both glucose and fructose (bxk1 HXK2 glk.1), activation of trehalase was observed with both sugars (Fig. 1). In a triple sugar kinase mutant (bxk1 bxk2 glk1) neither glucose nor fructose caused activation of trehalase (Fig. 1).

On the other hand, in stationary-phase cells obtained in the presence of glucose, no requirement for phosphorylation of the sugar was observed. When yeast cells are starved for nitrogen on a glucose-containing medium, they enter the stationary phase $\mathrm{G} 0$ and accumulate a high level of trehalose. Re-addition of nitrogen triggers

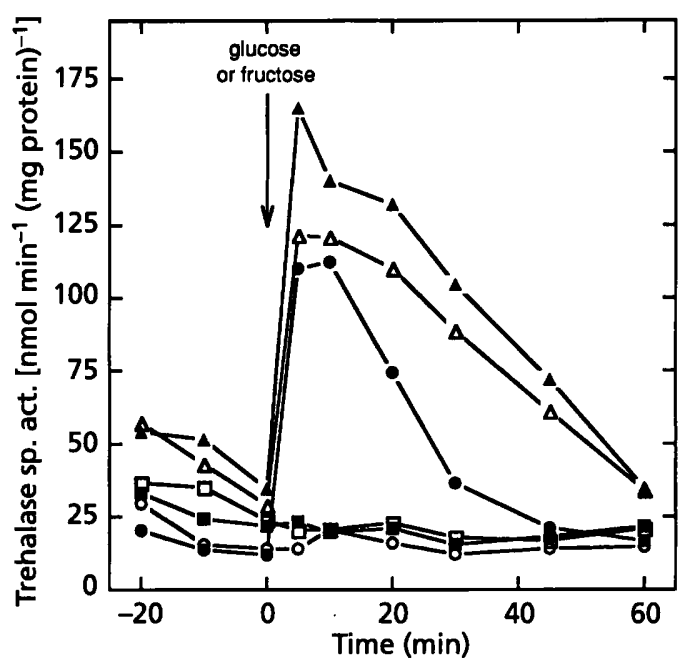

Fig. 1. Trehalase activity after addition of a fermentable sugar to exponential-phase glycerol-grown cells. 0,0 , Strain lacking both hexokinase PI and PII but not glucokinase ( $h \times k 1 h \times k 2)$ (O, addition of $4 \%$ glucose; $O$, addition of $4 \%$ fructose). $\Delta, \triangle$, Strain lacking glucokinase and hexokinase PI (hxk1 glk1) (A addition of $4 \%$ glucose; $\triangle$, addition of $4 \%$ fructose). $\square, \square$, Strain lacking glucokinase and both hexokinase PI and PII ( $h \times k 1$ $h \times k 2$ glk1) (, , addition of $4 \%$ glucose; $\square$, addition of $4 \%$ fructose).

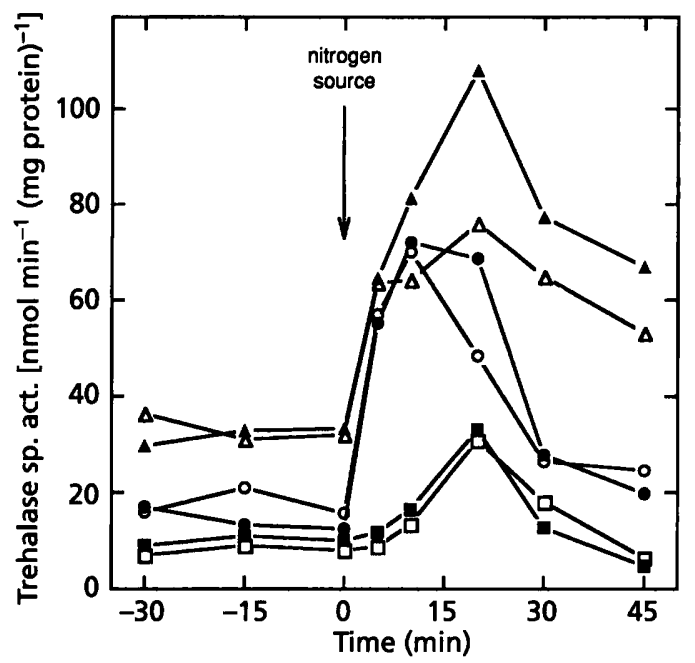

Fig. 2. Trehalase activity after addition of a nitrogen source (10 $\mathrm{mM}$ asparagine and essential amino acids) in the presence of a fermentable sugar to nitrogen-starved glucose-grown cells. 0, $0, \square$, Strain lacking both hexokinase PI and PII (hxk1 hxk2) (O. presence of $4 \%$ glucose; $O$, presence of $4 \%$ fructose; $\square$ no sugar present). $\Delta, \triangle, \square$, Strain lacking glucokinase and hexokinase PI (hxk1 glk1) ( $\Delta$, presence of $4 \%$ glucose; $\triangle$, presence of $4 \%$ fructose; $\square$, no sugar present).

approximately fivefold activation of trehalase within 10-20 min, causing rapid mobilization of trehalose concomitant with the initiation of growth. This nitrogeninduced activation is largely dependent on the presence of a rapidly fermented sugar like glucose or fructose (Hirimburegama et al., 1992; Durnez et al., 1994; Fig. 2). 
(a)
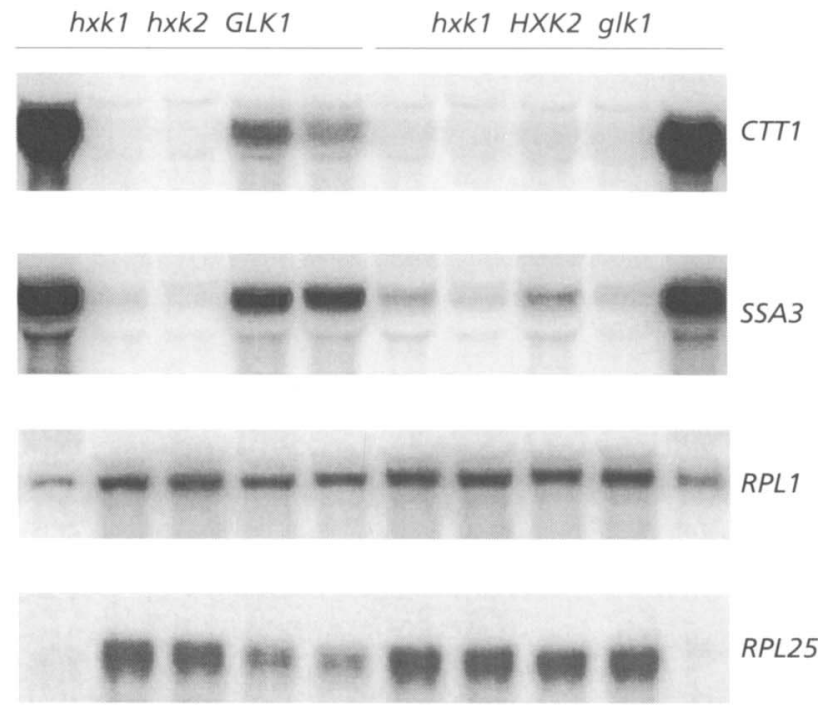

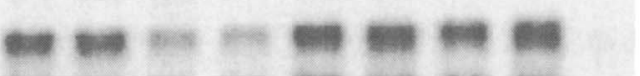

RPS33

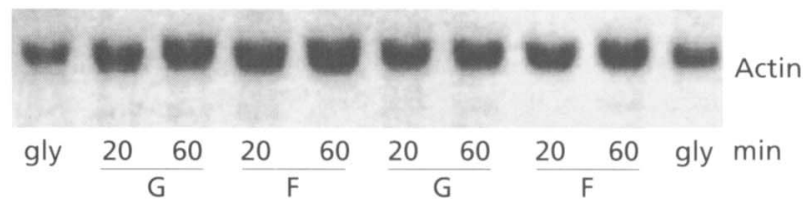

(b)

$h \times k 1 h \times k 2$ GLK1
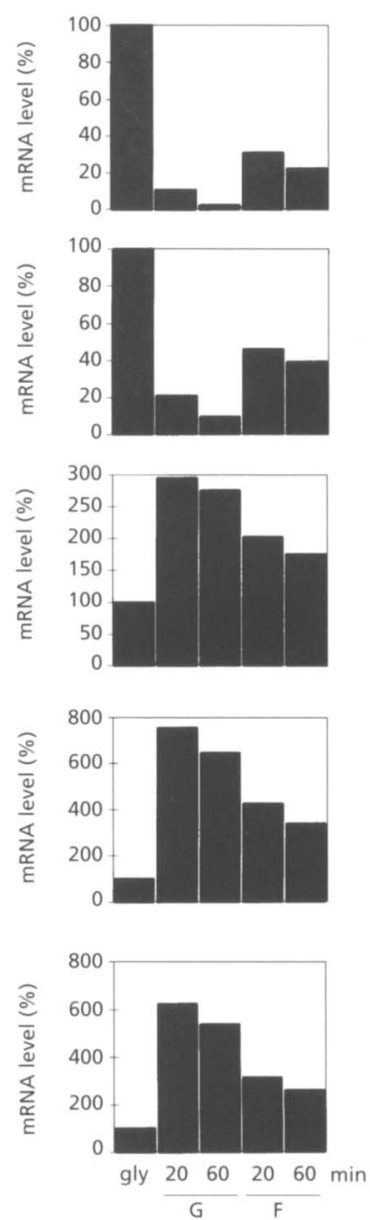

hxk1 HXK2 glk1
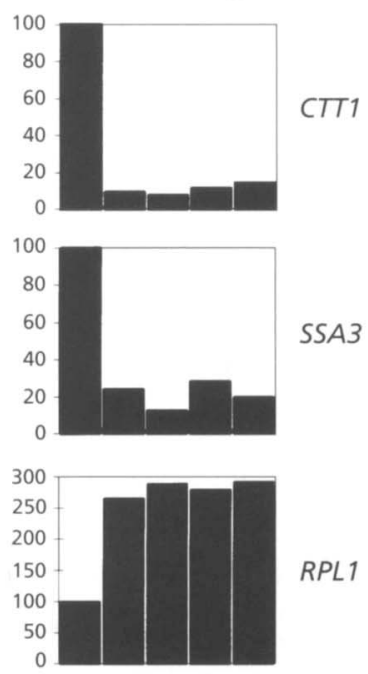

RPL1
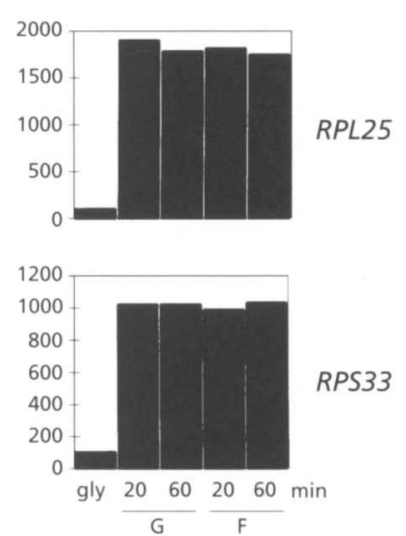

Fig. 3. (a) Northern blot analysis of the expression of CTT1 (catalase T), SSA3 (heat shock protein Hsp70) and the ribosomal protein genes RPL1, RPL25 and RPS33 after addition of $2 \%$ glucose (G) or $2 \%$ fructose (F) for 20 min or 60 min to exponential-phase glycerol-grown cells (gly) of yeast strains either lacking both hexokinase PI and PII but not glucokinase ( $h \times k 1$ hxk2 GLK1) or lacking glucokinase and hexokinase PI (h:k1 HXK2 glk1). Actin messenger levels are shown as control. (b) Quantification of the results in (a). Actin messenger levels were used for calibration.

When a nitrogen source was added to nitrogen-starved cells of a $b x k 1 b x k 2$ GLK1 strain incubated in the presence of glucose or fructose, rapid activation of trehalase was not only observed with glucose but also with fructose, which cannot be phosphorylated in this strain (Fig. 2). Also in a strain able to phosphorylate both glucose and fructose ( $b \times k 1$ HXK2 glk 1 ) both sugars caused activation of trehalase (Fig. 2). In all cases the activation was dependent to a large extent on the presence of both the nitrogen and the sugar (Fig. 2), as reported previously (Hirimburegama et al., 1992; Durnez et al., 1994). [Since a triple sugar kinase mutant ( $b \times k 1 b \times k 2$ glk1) cannot grow on glucose or fructose, the experiment in which nitrogen is added to glucose-grown nitrogenstarved cells could not be performed with this strain.] These results show that activation of trehalase in glucosegrown cells by a combination of fermentable sugar and nitrogen, i.e. through the fermentable-growth-medium induced pathway, does not depend on phosphorylation and by extension not on metabolism of the fermentable sugar.

When wild-type yeast cells are growing on a nonfermentable carbon source, expression of the genes CTT1 and $S S A 3$ is much higher than on a rapidly-fermented sugar like glucose or fructose (Bissinger et al., 1989; Werner-Washburne et al., 1989). Addition of glucose for $20 \mathrm{~min}$ or $60 \mathrm{~min}$ to cells of strains ( $b \times k 1$ bxk 2 GLK1 and $b \times k 1$ HXK2 glk1) able to phosphorylate the glucose caused complete disappearance of the CTT1 and SSA3 messengers (Fig. 3). The CTT1 messenger was somewhat more sensitive than the $S S A 3$ messenger (Fig. 3). However, in the case of fructose complete disappearance of the CTT1 and $S S A 3$ messengers during this time period was only observed in the bxk1 HXK2 glk1 strain, which can phosphorylate the fructose. In the $b \times k 1 b \times k 2$ GLK1 strain, a strong signal remained for both $C T T 1$ and $S S A 3$ after $20 \mathrm{~min}$ and $60 \mathrm{~min}$ in the presence of fructose 
(a)

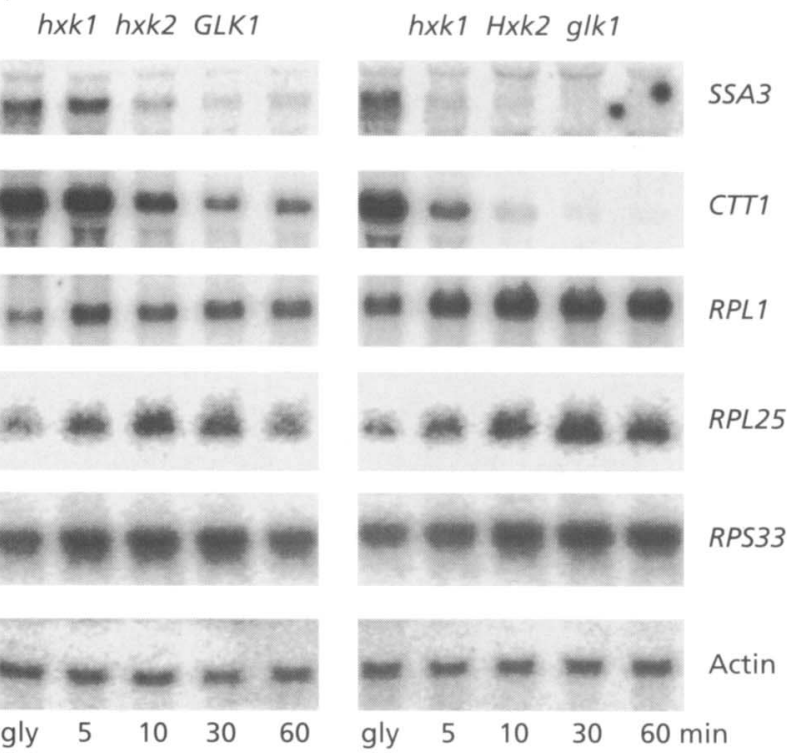

(b) $h \times k 1 h \times k 2$ GLK1

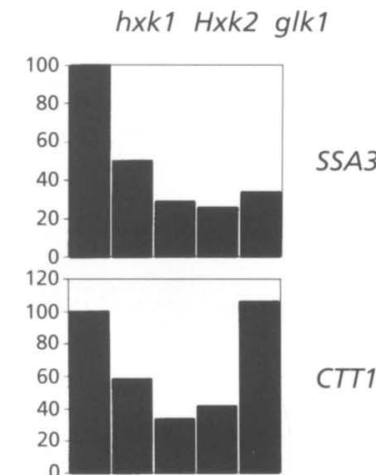

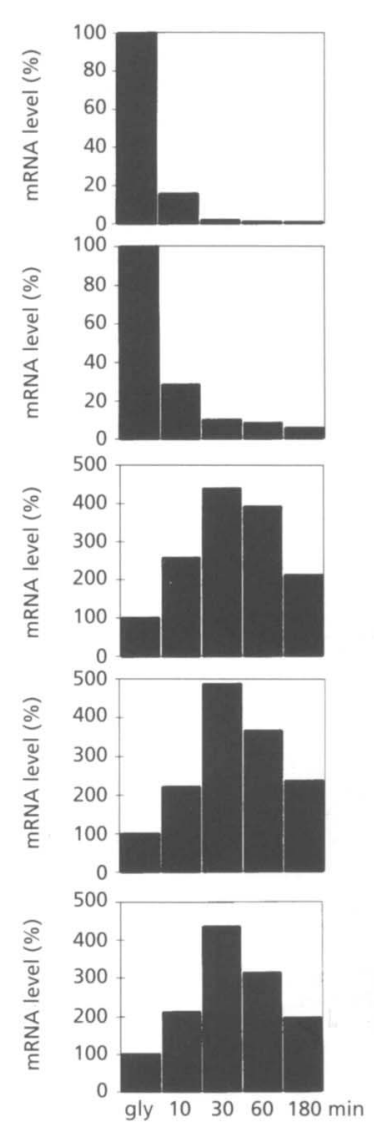

SSA3
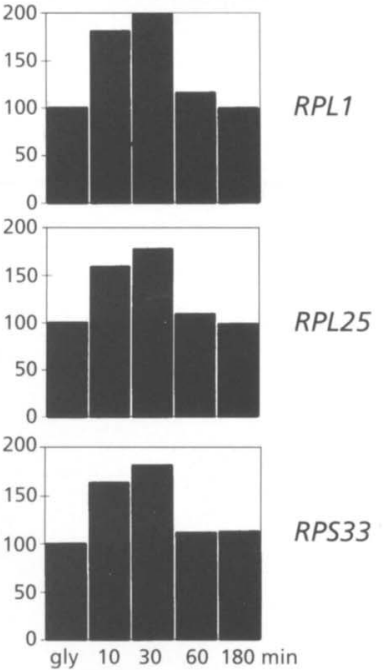

Fig. 4. (a) Northern blot analysis of the expression of SSA3 (heat shock protein Hsp70), CTT1 (catalase T) and the ribosomal protein genes RPL1, RPL25 and RPS33 after addition of $2 \%$ glucose for $5,10,30$ and 60 min to exponentialphase glycerol-grown cells of yeast strains (W303-1A background) either lacking both hexokinases ( $h \times k 1 h \times k 2$ GLK1) or lacking both hexokinases and also glucokinase ( $h \times k 1 h \times k 2 \mathrm{~g} / k 1)$. Actin messenger levels are shown as control. (b) Quantification of Northern blot analysis of the expression of SSA3 (heat shock protein Hsp70), CTT1 (catalase T) and the ribosomal protein genes RPL1, RPL25 and RPS33 after addition of $2 \%$ glucose for 10,30 and 60 min to exponential-phase glycerol-grown cells of a yeast strain (WAY.glk1-1A) lacking only both hexokinases ( $h \times k 1 h \times k 2$ GLK1) or a strain (PD1501) lacking both hexokinases and also glucokinase ( $h \times k 1 h \times k 2 \mathrm{glk1}$ ). Actin messenger levels were used for calibration.

(Fig. 3). In a triple sugar kinase mutant ( $b \times k 1$ bxk2 glk1) there was a significant delay in the glucose-induced disappearance of the messengers compared to the strain with an active glucokinase ( $b \times k 1$ bxk2 GLK1; Fig. 3), which can phosphorylate the glucose (Fig. 4). This was also observed in another strain background (W303-1A) (Fig. 4). These results suggest the existence of two pathways causing repression, one pathway dependent on sugar phosphorylation and the other independent of it.

Expression of all ribosomal protein genes is tightly coupled to the growth rate. In cells growing slowly on a nonfermentable carbon source the expression is low. Addition of glucose causes, within a few minutes, a rapid 5-10-fold induction ('upshift') of the whole spectrum of ribosomal protein genes (Pearson \& Haber, 1980; Kief \& Warner, 1981; Donovan \& Pearson, 1986; Mager \& Planta, 1991). We measured the upshift of RPL1, RPL25 and RPS33 (Fig. 3). The genes RPL1 and RPL25 are controlled by Rap1 whereas RPS 33 is controlled by Abf1.
Addition of glucose or fructose for $20 \mathrm{~min}$ or $60 \mathrm{~min}$ to cells of the bxk1 bxk2 GLK1 or bxk1 HXK2 glk1 strains triggered a significant upshift in expression of the ribosomal protein genes RPL1, RPL25 and RPS33. However, when the sugar cannot be phosphorylated (fructose in the $b \times k 1 b x k 2$ GLK1 strain) the upshift was only partial (about two- to threefold). This was also observed for the glucose-induced upshift in two different strain backgrounds in the time-course experiment shown in Fig. 4.

In stationary-phase yeast cells previously grown on YPD and then starved for nitrogen on a glucose-containing medium, the expression of $C T T 1$ and $S S A 3$ was much higher while the expression of RPL1, RPL25 and RPS33 was much lower than in cells growing exponentially on glucose (Fig. 5). This was observed both in a bxk1 bxk2 GLK1 strain and in a $b \times k 1 \mathrm{HXK} 2 \mathrm{glk} 1$ strain. Addition of a nitrogen source for $60 \mathrm{~min}$ in the presence of glucose or fructose to these strains caused disappearance of the 


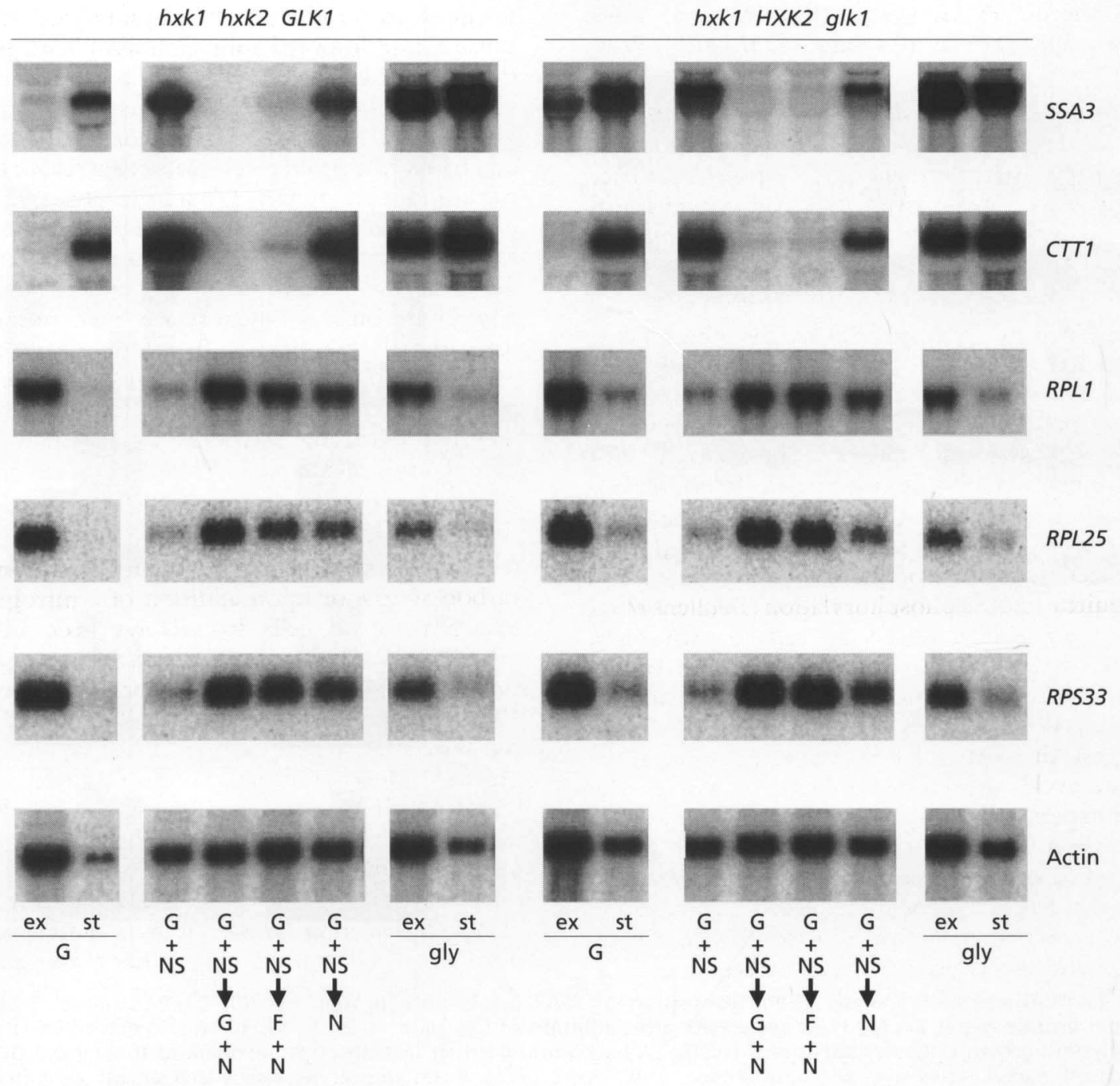

Fig. 5. Northern blot analysis of the expression of SSA3 (heat shock protein Hsp70), CTT1 (catalase T) and the ribosomal protein genes $R P L 1, R P L 25$ and $R P S 33$ after addition of a nitrogen source [10 $\mathrm{mM}\left(\mathrm{NH}_{4}\right)_{2} \mathrm{SO}_{4}$ and essential amino acids] for $60 \mathrm{~min}$ in the presence of glucose $(\mathrm{G}+\mathrm{NS} \rightarrow \mathrm{G}+\mathrm{N})$ or fructose $(\mathrm{G}+\mathrm{NS} \rightarrow \mathrm{F}+\mathrm{N})$ to cells starved for nitrogen on a glucosecontaining medium (G + NS) of strains either lacking both hexokinases but not glucokinase ( $h x k 1$ hxk2 GLK1) or lacking glucokinase and hexokinase PI ( $h \times k 1$ HXK2 g/k1). The expression in the absence of sugar $(\mathrm{G}+\mathrm{NS} \rightarrow \mathrm{N})$ and in exponentialphase (ex) and stationary-phase (st) glucose-grown (G) and glycerol-grown (gly) cells is shown for comparison. Actin messenger levels are shown as control.

CTT1 and SSA3 messengers and a strong induction of the RPL1, RPL25 and RPS33 messengers (Fig. 5). Addition of nitrogen alone also caused disappearance of the CTT1 and SSA3 messengers to some extent but much less than in the presence of (phosphorylated or unphosphorylated) sugar (the $C T T 1$ message dropped to about $52 \%$ instead of to about $7 \%$ while the $S S A 3$ message dropped to about $24 \%$ instead of to about $5 \%$ ). For the upshift in ribosomal gene expression there was no significant difference between addition of nitrogen alone and addition of nitrogen plus unphosphorylated sugar.

\section{DISCUSSION}

The results presented in this paper show that in G0 cells starved for nitrogen on a glucose-containing medium, none of the nitrogen-induced and glucose- (or fructose-) dependent regulatory responses is entirely dependent on phosphorylation of the sugar. In addition, fermentablesugar-induced repression of $C T T 1$ and $S S A 3$ and upshift of ribosomal protein synthesis in cells growing on a nonfermentable carbon source also to a significant extent does not require phosphorylation of the sugar. These are the first biochemically defined regulatory responses in yeast cells which depend on the presence of a rapidly fermented sugar without the need for any metabolism of the sugar. They might be involved in the previously described physiological and cell cycle effects caused by unphosphorylated glucose (Granot \& Synder, 1991, 1993). All glucose-induced regulatory responses studied up to now depended at least on phosphorylation of the sugar by one of the three known glucose-phosphorylating 
enzymes (Gancedo \& Gancedo, 1979; Entian, 1986; Beullens et al., 1988; Becher dos Passos et al., 1992; Boles et al., 1993).

The lack of a requirement for sugar phosphorylation in activation of the fermentable-growth-medium-induced pathway indicates that the regulatory responses induced by this pathway are not triggered by enhanced availability of energy or biosynthetic capacity derived from the glucose. Apparently, the dependence on glucose is due to specific detection of the glucose in the medium.

We have obtained evidence previously that the glucose dependency of nitrogen-plus-glucose-induced activation of trehalase is not due to a requirement of glucoseinduced activation of the Ras-adenylate cyclase pathway (Thevelein \& Beullens, 1985; Thevelein, 1991; Hirimburegama et al., 1992; Durnez et al., 1994). This is also suggested by the present finding that there is no requirement for phosphorylation of the sugar, since glucose-induced activation of the Ras-adenylate cyclase pathway requires glucose phosphorylation (Beullens et al., 1988). When glucose is added to cells grown on a nonfermentable carbon source, phosphorylation of the sugar is required for activation of trehalase (Fig. 1) and for the rapid repression of $C T T 1$ and $S S A 3$ (Fig. 3). These results suggest that glucose-induced activation of the Ras-adenylate cyclase pathway might be involved. The time-course experiments of glucose-induced CTT1 and $S S A 3$ repression (Fig. 4) suggest a model in which glucose-induced, phosphorylation-dependent activation of the Ras-adenylate cyclase pathway causes a rapid effect while the fermentable-growth-medium-induced, sugarphosphorylation-independent pathway affects the same targets but more slowly. Obviously, the two pathways together can also cause a stronger final response and not just a faster one. There has been controversy concerning the involvement of the Ras-adenylate cyclase pathway as mediator of the glucose-induced upshift in ribosomal protein gene expression (Kraakman et al., 1993; Griffioen et al., 1994; Klein \& Struhl, 1994). Our result that the upshift is to a significant extent independent of glucose phosphorylation is in contradiction with at least exclusive mediation by the Ras-adenylate cyclase pathway, since glucose phosphorylation is required for stimulation of this pathway (Beullens et al., 1988).

Up to now, nutrient control of $C T T 1, S S A 3$ and several co-regulated genes has mainly been interpreted in the light of the existence of an alternative stress-induced (STRE) pathway which is different from the classical heat shock factor (HSF) controlled pathway (Kobayashi \& McEntee, 1990, 1993; Wieser et al., 1991; Marchler et al., 1993). In this view, induction of this series of genes in stationary-phase cells is considered to be a response to 'starvation stress'. Any deviation from the optimal growth condition would lead to induction and hence the major control on expression would be exerted by a stresscontrolled pathway rather than a nutrient-controlled pathway. A consequence of this model is that suboptimal nutrient conditions are in some way detected by a stresssensing system. Our results, on the other hand, show that nutrient-induced repression of $C T T 1$ and $S S A 3$ is not a response to termination of physiological starvation because the addition of nonmetabolizable glucose is unable to lift physiological starvation. It is clear that the presence of nonmetabolizable glucose instead of metabolizable glucose is a strong deviation from the optimal growth condition and still the cell reacts as if the optimal growth condition were present. Therefore, this result tentatively points to a nutrient-controlled pathway as the major control system, in which the presence of the nutrients is detected by specific sensing systems and the stress conditions only secondarily or even unspecifically interfere with the proper functioning of the signalling pathway. Since addition of nitrogen alone also causes partial effects, it appears that different nutrients trigger different signalling pathways which finally converge to give the full response.

It is not surprising that the upshift in ribosomal protein synthesis which occurs upon addition of a rapidly fermentable sugar to cells growing on a nonfermentable carbon source or upon addition of a nitrogen source to nitrogen-starved cells has always been interpreted in relation to the induction or stimulation of growth under these conditions (Pearson \& Haber, 1980; Kief \& Warner, 1981; Mager \& Planta, 1991; Raue \& Planta, 1991; Kraakman et al., 1993; Klein \& Struhl, 1994). The glucose-induced upshift in cells growing on a nonfermentable carbon source might consist of two phases, an initial rapid phase independent of metabolism and a longterm maintenance effect dependent on metabolism (Griffioen et al., 1994). Our results (Fig. 4) are in agreement with this view. They also show that the initial upshift in ribosomal protein synthesis is not a consequence of a change in the cellular growth rate, causing, for example, a higher demand for protein synthesis, since unphosphorylated glucose cannot support faster growth. These data support the view that the growth rate in yeast is regulated by mechanisms independent of growth itself. Using different approaches, Ju \& Warner (1994) have recently arrived at a similar conclusion.

\section{ACKNOWLEDGEMENTS}

We wish to thank K.-D. Entian (Frankfurt, Germany) for the gift of yeast strains, and P. Durnez and S. Hohmann for the construction of some of the strains used in this work. J.W. gratefully acknowledges receipt of a fellowship from the Belgian National Fund for Scientific Research. This work was supported by grants from the Belgian National Fund for Scientific Research (FGWO), the Belgian National Lottery, the Research Fund of the Katholieke Universiteit te Leuven, the European Commission (Human Capital and Mobility Programme CHRXCT93-0265) and the Belgian Office for Cooperation with Developing Countries (ABOS).

\section{REFERENCES}

Becher dos Passos, J., Vanhalewyn, M., Brandăo, R. L., Castro, I. M., Nicoli, J. R. \& Thevelein, J. M. (1992). Glucose-induced activation of plasma membrane $\mathrm{H}^{+}$-ATPase in mutants of the yeast Saccharomyces cerevisiae affected in cAMP metabolism, cAMPdependent protein phosphorylation and the initiation of glycolysis. Biochim Biophys Acta 1136, 57-67.

Beullens, M., Mbonyi, K., Geerts, L., Gladines, D., Detremerie, K., 
Jans, A. W. H. \& Thevelein, J. M. (1988). Studies on the mechanism of the glucose-induced cAMP-signal in glycolysis- and glucose repression-mutants of the yeast Saccharomyces cerevisiae. Eur J Biochem 172, 227-231.

Bissinger, P. H., Wieser, R., Hamilton, B. \& Ruis, H. (1989). Control of Saccharomyces cerevisiae catalase T gene (CTT1) expression by nutrient supply via the RAS-cyclic AMP pathway. Mol Cell Biol 9 , $1309-1315$.

Boles, E., Heinisch, J. \& Zimmermann, F. K. (1993). Different signals control the activation of glycolysis in the yeast Saccbaromyces cerevisiae. Yeast 9, 761-770.

Donovan, D. M. \& Pearson, N. J. (1986). Transcriptional regulation of ribosomal proteins during a nutritional upshift in Saccharomyces cerevisiae. Mol Cell Biol 6, 2429-2435.

Durnez, P., Pernambuco, M. B., Oris, E., Arguelles, J.-C., Mergelsberg, H. \& Thevelein, J. M. (1994). Activation of trehalase during growth induction by nitrogen sources in the yeast Saccharomyces cerevisiae depends on the free catalytic subunits of cAMPdependent protein kinase, but not on functional Ras proteins. Yeast 10, 1049-1064.

Entian, K. D. (1986). Glucose repression: a complex regulatory system in yeast. Microbiol Sci 3, 366-371.

Entian, K. D., Droll, L. \& Mecke, D. (1983). Studies on rapid reversible and non-reversible inactivation of fructose-1,6bisphosphatase and malate dehydrogenase in wild-type and glycolytic block mutants of Saccharomyces cerevisiae. Arch Microbiol 134, 187-192.

Fraenkel, D. G. (1982). Carbohydrate metabolism. In The Molecular Biology of the Yeast Saccharomyces. Metabolism and Gene Expression, pp. 1-37. Edited by J. N. Strathern, E. W. Jones \& J. R. Broach. Cold Spring Harbor, NY: Cold Spring Harbor Laboratory.

François, J., Villanueva, M. E. \& Hers, H. G. (1988). The control of glycogen metabolism in yeast. 1 . Interconversion in vivo of glycogen synthase and glycogen phosphorylase induced by glucose, a nitrogen source or uncoupler. Eur J Biochem 174, 551-559.

Gancedo, J. M. \& Gancedo, C. (1979). Inactivation of glyconeogenic enzymes in glycolytic mutants of Saccharomyces cerevisiae. Eur J Biochem 101, 455-460.

Granot, D. \& Snyder, M. (1991). Glucose induces cAMPindependent growth-related changes in stationary-phase cells of Saccharomyces cerevisiae. Proc Natl Acad Sci US A 88, 5724-5728.

Granot, D. \& Snyder, M. (1993). Carbon source induces growth of stationary phase yeast cells, independent of carbon source metabolism. Yeast 9, 465-479.

Griffioen, G., Mager, W. H. \& Planta, R. J. (1994). Nutritional upshift response of ribosomal protein gene transcription in Saccharomyces cerevisiae. FEMS Microbiol Lett 123, 137-144.

Hirimburegama, K., Durnez, P., Keleman, J., Oris, E., Vergauwen, R., Mergelsberg, H. \& Thevelein, J. M. (1992). Nutrient-induced activation of trehalase in nutrient-starved cells of the yeast Saccharomyces cerevisiae. cAMP is not involved as second messenger. $J$ Gen Microbiol 138, 2035-2043.

Ju, Q. \& Warner, J.R. (1994). Ribosome synthesis during the growth cycle of Saccharomyces cerevisiae. Yeast 10, 151-157.

Kief, D. R. \& Warner, J. R. (1981). Coordinate control of syntheses of ribosomal ribonucleic acid and ribosomal proteins during nutritional shift-up in Saccharomyces cerevisiae. Mol Cell Biol 1, $1007-1015$.

Klein, C. \& Struhl, K. (1994). Protein kinase A mediates growthregulated expression of yeast ribosomal protein genes by modulating RAP1 transcriptional activity. Mol Cell Biol 14, 1920-1928.
Kobayashi, N. \& McEntee, K. (1990). Evidence for a heat shock transcription factor-independent mechanism for heat shock induction of transcription in Sacharomyces cerevisiae. Proc Natl Acad Sci US A 87, 6550-6554.

Kobayashi, N. \& McEntee, K. (1993). Identification of cis and trans components of a novel heat shock stress regulatory pathway in Saccharomyces cerevisiae. Mol Cell Biol 13, 248-256.

Kraakman, L. S., Griffioen, G., Zerp, S., Groeneveld, P., Thevelein, J. M., Mager, W. H. \& Planta, R. J. (1993). Growth-related expression of ribosomal protein genes in Saccbaromyces cerevisiae. Mol Gen Genet 239, 196-204.

Mager, W. H. \& Planta, R. J. (1991). Coordinate expression of ribosomal protein genes in yeast as a function of cellular growth rate. Mol Cell Biochem 104, 181-187.

Marchler, G., Schuller, C., Adam, G. \& Ruis, H. (1993). A Saccharomyces cerevisiae UAS element controlled by protein kinase A activates transcription in response to a variety of stress conditions. EMBO J 12, 1997-2003.

Pearson, N. J. \& Haber, J. E. (1980). Changes in regulation of ribosomal protein synthesis during vegetative growth and sporulation of Saccharomyces cerevisiae. J Bacteriol 143, 1411-1419.

Raue, H. A. \& Planta, R. J. (1991). Ribosome biogenesis in yeast. Prog Nucleic Acid Res Mol Biol 41, 89-129.

Sherman, F., Fink, G. R. \& Hicks, J. B. (1986). Methods in Yeast Genetics. Cold Spring Harbor, NY : Cold Spring Harbor Laboratory.

Thevelein, J. M. (1984). Cyclic-AMP content and trehalase activation in vegetative cells and ascospores of yeast. Arch Microbiol 138, 64-67.

Thevelein, J. M. (1991). Fermentable sugars and intracellular acidification as specific activators of the RAS adenylate cyclase signalling pathway in yeast - the relationship to nutrient-induced cell cycle control. Mol Microbiol 5, 1301-1307.

Thevelein, J. M. \& Beullens, M. (1985). Cyclic AMP and the stimulation of trehalase activity in the yeast Saccharomyces cerevisiae by carbon sources, nitrogen sources and inhibitors of protein synthesis. J Gen Microbiol 131, 3199-3209.

Thevelein, J. M. \& Hohmann, S. (1995). Trehalose synthase: guard to the gate of glycolysis in yeast? Trends Biochem Sci 20, 3-10.

Van der Plaat, J. B. (1974). Cyclic 3',5'-adenosine monophosphate stimulates trehalose degradation in baker's yeast. Biochem Biophys Res Commun 56, 580-587.

Walsh, R. B., Clifton, D., Horak, J. \& Fraenkel, D. G. (1991). Saccharomyces cerevisiae null mutants in glucose phosphorylation: metabolism and invertase expression. Genetics 128, 521-527.

Werner-Washburne, M., Becker, J., Kosic-Smithers, J. \& Craig, E. A. (1989). Yeast Hsp70 RNA levels vary in response to the physiological status of the cell. $J$ Bacteriol 171, 2680-2688.

Werner-Washburne, M., Braun, E., Johnston, G. C. \& Singer, R. A. (1993). Stationary phase in the yeast Saccharomyces cerevisiae. Microbiol Rev 57, 383-401.

Wieser, R., Adam, G., Wagner, A., Schuller, C., Marchiler, G., Ruis, H., Krawiec, Z. \& Bilinski, T. (1991). Heat shock factor-independent heat control of transcription of the CTT1 gene encoding the cytosolic catalase $\mathrm{T}$ of Saccharomyces cerevisiae. J Biol Chem 266, 12406-12411.

Received 27 September 1995; revised 26 January 1996; accepted 6 February 1996. 